\title{
Neutron-induced Rat Mammary Carcinomas Are Mainly of Luminal Subtype and Have Multiple Copy Number Aberrations
}

\author{
HITOMI MORIYAMA ${ }^{1,2}$, KAZUHIRO DAINO $^{2}$, TATSUHIKO IMAOKA ${ }^{1,2}$, MAYUMI NISHIMURA $^{2}$, \\ YUKIKO NISHIMURA ${ }^{2}$, MASARU TAKABATAKE ${ }^{1,2}$, TAKAMITSU MORIOKA $^{2}$, \\ MASAHIRO FUKUSHI ${ }^{1}$, YOSHIYA SHIMADA ${ }^{3}$ and SHIZUKO KAKINUMA ${ }^{2}$ \\ ${ }^{1}$ Department of Radiological Sciences, Graduate School of Human \\ Health Sciences, Tokyo Metropolitan University, Tokyo, Japan; \\ ${ }^{2}$ Department of Radiation Effects Research, National Institute of Radiological Sciences, \\ National Institutes for Quantum and Radiological Science and Technology, Chiba, Japan; \\ ${ }^{3}$ National Institutes for Quantum and Radiological Science and Technology, Chiba, Japan
}

\begin{abstract}
Background/Aim: Neutrons are used as a type of high linear energy transfer (LET) radiation and they have stronger carcinogenic effects compared to low LET radiation. We sought to clarify the features of mammary carcinomas for which the incidence increases when these were exposed to neutron radiation. Materials and Methods: We compared mammary carcinomas from female Sprague-Dawley rats irradiated at 7 weeks of age with 0.485 Gy neutron beams or $0.5-$-Gy $\gamma$ rays, with carcinomas of non-irradiated rats. Tumors were classified into luminal and non-luminal subtypes based on immunohistochemistry, while their copy number aberrations were determined using microarrays. Results: Neutrons and $\gamma$ rays significantly increased the incidence of luminal carcinomas. The carcinomas in the three groups contained multiple aberrations affecting 46 genes for which mutations have been reported in human breast cancer. Conclusion: Neutrons and $\gamma$ rays increase the incidence of luminal mammary carcinoma in rats, probably via genetic aberrations similar to those found in human breast cancer patients.
\end{abstract}

Exposure to radiation increases the risk of breast cancer, as revealed by epidemiological studies of atomic bomb survivors and patients who have undergone radiotherapy (1). Neutrons can

This article is freely accessible online.

Correspondence to: Shizuko Kakinuma and Kazuhiro Daino, Department of Radiation Effects Research, National Institute of Radiological Sciences, National Institutes for Quantum and Radiological Science and Technology, 4-9-1 Anagawa, Inage-ku, Chiba 263-8555, Japan. Tel. +81 432064053, Fax: +81 432064138, e-mail: kakinuma.shizuko@qst.go.jp,daino.kazuhiro@qst.go.jp

Key Words: Neutron, breast cancer, subtype, copy number aberration. be used as a type of high linear energy transfer (LET) radiation and produce more complex DNA damage with stronger carcinogenic effects compared to low LET radiation (2). In clinical settings, neutrons are generated as a secondary type of radiation during proton therapy (3), However, the carcinogenic effects of neutrons in humans have not yet been reported.

Cancer is caused by the accumulation of genomic and epigenomic alterations, such as gene mutations, chromosomal and DNA copy number aberrations in addition to DNA methylation $(4,5)$. Rats develop mammary carcinomas that are similar to human breast cancer with regard to their hormone dependence and pathology (6) and thus have been used as a model of radiation-induced breast cancer (7). Moreover, various animal experiments have revealed that neutrons have a strong effect on mammary carcinogenesis (8). Other studies have revealed various genomic and epigenomic alterations in radiation-induced cancers $(9,10)$. Although copy number aberrations are common in many types of tumors, there are only a few findings on genetic alterations of cancers induced by neutrons (11).

Breast cancer is a heterogeneous disease associated with genomic alterations and is classified into subtypes such as luminal, triple-negative, and human epidermal growth factor receptor 2 (HER2)-enriched (12). A few studies have investigated the subtypes of breast cancer that occur after X-ray exposure (13-15), however, the results are inconsistent. Furthermore, although other studies have assessed the incidence of mammary carcinoma after exposure to neutrons (2), none have described the subtypes of cancer advancing following radiation, while it is unclear which subtype(s) contributes to the increased risk of breast cancer caused by it.

We have previously conducted a series of experiments to quantify the incidence of neutron-induced mammary carcinomas in rats $(16,17)$. In our present study, we further analysed the mammary carcinomas from those experiments 
to understand the subtype(s) of these carcinomas for which the incidence was increased following neutron exposure. We also clarified the DNA copy number aberrations of these mammary carcinomas to elucidate the mechanisms of neutron-induced carcinogenesis.

\section{Materials and Methods}

Tissue samples. Tumor samples were obtained from our previous study (8), which was approved by the Institutional Animal Care and Use Committee of National Institute of Radiological Sciences. Briefly, in that previous study, 7-week-old female Jcl:SD rats (Clea Japan Inc., Tokyo, Japan) were whole-body irradiated with ${ }^{9} \mathrm{Be}(\mathrm{d}, \mathrm{n} \gamma){ }^{10} \mathrm{~B}$ fast neutrons (mean energy, $2 \mathrm{MeV}$ ) or ${ }^{137} \mathrm{Cs} \gamma$ rays, and mammary carcinoma development was assessed by weekly palpation until the age of 90 weeks. All of the carcinomas available from the neutron-irradiated $(0.485 \mathrm{~Gy}, \mathrm{n}=16), \gamma$-ray-irradiated $(0.5$ $\mathrm{Gy}, \mathrm{n}=14)$, and the matched untreated rats $(\mathrm{n}=28)$, excluding the ones from rats found dead, were analysed.

Immunostaining and classification of tumor subtypes. Formalinfixed, paraffin-embedded tissue sections were immunostained with antibodies against the estrogen receptor (ER) $\alpha$ (clone 6F11, Leica Biosystems, Nussloch, Germany; dilution, 1:400), the progesterone receptor (PgR; clone SP42, Acris Antibodies, Herford, Germany; 1:400), HER2 (a mixture of clones e2-4001 and 3B5, Thermo Fisher Scientific, Waltham, MA, USA; 1:100), and the proliferation marker Ki-67 (clone SP6, Spring Bioscience, Pleasanton, CA, USA; 1:200) as previously described (17). Each slide was scanned using a NanoZoomer XR C12000-03 slide scanner (Hamamatsu Photonics, Hamamatsu, Japan), and all images were saved in NDPI format. Images of 6 regions of interest (ROI) per slide were captured independently by two researchers (i.e., 12 ROIs for each carcinoma) at $40 \times$ magnification using the NDP.view2 software (Hamamatsu Photonics) and were stored in JPEG format. The percentage of antigen-positive epithelial tumor cells was determined using the Tissue Studio version 3.6.1 software (Definiens, Munich, Germany) for automated scoring and averaging over the 12 ROIs. For ER $\alpha$ and $\mathrm{PgR}$, the cutoff for positivity of a tumor was set at $1 \%$ (12). For $\mathrm{Ki}-67$, the cutoff was set at the median percentage (14.8\%) (12). For HER2, tumors were classified as previously described (12). Luminal and non-luminal tumor subtypes were defined according to the standard classification criteria of human breast cancer (12), i.e., luminal subtype is defined as positive for either ER $\alpha$ or PgR and negative for HER2, and non-luminal subtype defined as any other.

Laser microdissection and DNA extraction. Neoplastic epithelial cells were collected using a laser microdissection system (MMI CellCut, Molecular Machines \& Industries, Munich, Germany). Briefly, cryosections (20 $\mu \mathrm{m}$ thick) were prepared from frozen tissues embedded in an optimal cutting temperature compound (Sakura Finetek Japan, Tokyo, Japan) on membrane slides (MMI Membrane Slides, RNA free, Molecular Machines \& Industries). Following fixation in 2propanol for 45 seconds, sections were stained with hematoxylin and eosin. Dehydration was then achieved through a graded ethanol series and xylene for 15 seconds each. Neoplastic epithelial cells were subsequently dissected from the frozen sections and were collected. Since our preliminary examination indicated that $50 \mathrm{ng}$ of doublestranded DNA was retrievable from $1 \mathrm{~mm} 2$ of sectioned epithelial cells,, a total of $5 \mathrm{~mm} 2$ or more of epithelial cells were dissected for the analyses described below. DNA was extracted from dissected epithelial cell sections as well as from normal liver sections stained in the same manner as the carcinoma sections, which served as the source of reference DNA from the individual rats. DNA extraction was performed using a QIAmp DNA Micro kit (Qiagen, Hilden, Germany) and isolated DNA was collected in $20 \mu \mathrm{L}$ water (UltraPure DNase/RNase-Free Distilled Water, Thermo Fisher Scientific).

Microarray-based comparative genomic hybridization (aCGH). Double-stranded DNA (50 ng) was fragmented and amplified using the GenomePlex Whole Genome Amplification kit (Sigma-Aldrich, St. Louis, MO, USA). The amplified DNAs from normal liver and mammary carcinoma samples were labelled with cyanine 3- and cyanine 5-dUTP, respectively, and was purified using a purification column (Agilent Technologies, Santa Clara, CA, USA). Labelled DNA was hybridized with probes of microarrays (SurePrint G3 Rat CGH, $4 \times 180 \mathrm{~K}$; Agilent Technologies) at $67^{\circ} \mathrm{C}$ with rotation at $20 \mathrm{rpm}$ for 24 hours, and was then washed with Wash Buffers 1 and 2 (Agilent Technologies). The resolution of microarrays was $\sim 17.5 \mathrm{~kb}$ (as an average) with 155,049 probes. Microarray scanning was performed using the Agilent G2505C microarray scanner. Fluorescence intensity values were obtained from the scanned images with the Agilent Feature Extraction software (ver. 10.7.3.1) and were analysed using the Agilent Genomic Workbench software 7.0.4.0.

Statistical analysis. Statistical analysis was performed using the statistical software $\mathrm{R}$ with the aid of a graphical user interface EZR (Jichi Medical University, Saitama, Japan) (18). Comparison among three groups was performed using the Kruskal-Wallis test. Comparison between two groups was performed using the MannWhitney's $U$-test. A $p$-value of $<0.05$ was considered statistically significant.

\section{Results}

Neutrons and $\gamma$ rays increase the incidence of luminal carcinoma. We selected two groups of rats from our previous studies $(8,16)$ : i) irradiated with neutrons $(0.485 \mathrm{~Gy}, \mathrm{n}=24)$ and ii) with $\gamma$ rays $(0.5 \mathrm{~Gy}, \mathrm{n}=24)$ as well as a group of matched, non-irradiated rats $(n=76)$. Table I summarizes the incidence, tumor number, hazard ratio (i.e., ratio of the probabilities of having a new carcinoma per unit time), and the age at which mammary carcinomas were first detected in these groups. Exposure to either neutrons or $\gamma$-rays significantly increased the incidence and the hazard ratio, whereas neutron exposure also significantly reduced the age at which the carcinoma was first detected, as compared to the non-irradiated group (Table I).

To reveal the subtypes of mammary carcinomas in these groups of rats, we performed immunohistochemical staining for ER $\alpha, \mathrm{PgR}, \mathrm{HER} 2$, and Ki-67 in all available tumors. As expected, signals for ER $\alpha, \mathrm{PgR}$, and Ki-67 were observed in the nucleus, whereas the HER2 signal was in the plasma membrane (Figure 1A-D). The percentage of cells that were positive for each antigen did not differ significantly between groups (Figure 1E). Next, we classified all available mammary 
Table I. Characteristics of cohort of rats included in the present study.

\begin{tabular}{lccc}
\hline Feature & No irradiation & Neutrons & $\gamma$ rays \\
\hline Rats with carcinoma & $20 / 76(17 \%)$ & $16 / 24(63 \%)^{* * *}$ & $12 / 24(46 \%)^{*}$ \\
Carcinomas available & 31 & 27 & 19 \\
Hazard ratio [95\% CI] & 1 (reference) & $10.0[4.5-22.2]^{* * *}$ & $3.3[1.5-7.5]^{* *}$ \\
Weeks of age at detection & $67.8 \pm 16.9(17)^{\mathrm{a}}$ & $36.9 \pm 16.6 * * *(12)$ & $61.2 \pm 16.4(9)$ \\
\hline
\end{tabular}

${ }^{\mathrm{a}} \mathrm{Mean} \pm \mathrm{SD}$ (number of palpable carcinomas). ${ }^{*} p<0.05,{ }^{* *} p<0.01, * * * p<0.001 v s$. no irradiation.

Table II. Classification of available mammary carcinomas by immunohistochemical staining.

\begin{tabular}{|c|c|c|c|c|c|c|}
\hline \multicolumn{3}{|c|}{ Imuunohistochemistry result } & \multirow[t]{2}{*}{ Subtype $^{a}$} & \multicolumn{3}{|c|}{ Number of carcinomas } \\
\hline $\mathrm{ER} \alpha$ & $\mathrm{PgR}$ & HER2 SCORE & & No irradiation & Neutrons & $\gamma$ rays \\
\hline+ & + & $<3$ & $\mathrm{~L}$ & 10 & 8 & 7 \\
\hline+ & + & 3 & NL & 7 & 4 & 2 \\
\hline+ & - & $<3$ & $\mathrm{~L}$ & 4 & 2 & 1 \\
\hline+ & - & 3 & NL & 2 & 2 & 0 \\
\hline- & + & $<3$ & $\mathrm{~L}$ & 0 & 0 & 1 \\
\hline- & + & 3 & NL & 0 & 0 & 0 \\
\hline- & - & $<3$ & NL & 5 & 0 & 3 \\
\hline \multirow[t]{3}{*}{-} & - & 3 & NL & 0 & 0 & 0 \\
\hline & & Total & $\mathrm{L}$ & $14(50 \%)$ & $10(63 \%)$ & $9(64 \%)$ \\
\hline & & & NL & $14(50 \%)$ & $6(37 \%)$ & $5(36 \%)$ \\
\hline
\end{tabular}

a L, Luminal (defined as those positive for either ER $\alpha$ or PgR and negative for HER2); NL, non-luminal (defined as all others).

carcinomas with respect to being luminal or non-luminal, based on the immunohistochemistry results. The fractions of luminal carcinomas in the neutron- and $\gamma$-ray-irradiated groups tended to be higher compared to the non-irradiated group (Table II). The hazard ratio of luminal mammary carcinomas, which were palpable, was also significantly higher in the neutron- and $\gamma$-ray-irradiated groups compared to the non-irradiated group (Table III and Figure 2A). Neutron exposure also increased the hazard ratio of palpable nonluminal carcinomas at a marginally significant level and significantly reduced the age at first palpation of luminal and non-luminal carcinomas compared to the non-irradiated group (Table III and Figure 2B), although the number of non-luminal carcinomas was relatively small in the neutron-irradiated group. Taken together, the increased incidence of mammary carcinomas in the neutron-irradiated rats mostly involved luminal carcinomas.

Rat mammary carcinomas include copy number changes of genes associated with human breast cancer. We next performed an aCGH analysis of 16 mammary carcinomas (i) 7 from the non-irradiated, ii) 4 from the neutron-irradiated, and iii) 5 from the $\gamma$-ray-irradiated groups) to detect DNA copy number aberrations. We identified 99 aberrations: i) 42 in the non-irradiated: ii) 27 in the neutron-irradiated, and iii) 30 in the $\gamma$-ray-irradiated groups, none of which displayed any significant differences between them (Figure 3). Given that ionizing radiation is known to cause DNA strand breaks (19), we then focused on partial-chromosome copy number aberrations, excluding whole-chromosome aberrations, because the latter is more likely related to abnormal chromosome separation during mitosis $(20,21)$. The results indicated no significant difference in the number of partialchromosome aberrations among the non-irradiated, neutronirradiated, and $\gamma$-ray-irradiated groups (Table IV).

We subsequently examined whether these aberrations included genes important for the genesis of breast cancer. For this analysis, we focused on 92 rat orthologues of driver genes of human breast cancer, which have been previously reported in a study using next-generation sequencing (22). Our analysis indicated that 46 of the 92 genes were affected due to 11 partial- and 22 whole-chromosome aberrations in 7 carcinomas (data not shown). We further classified these 46 genes into: i) 13 proto-oncogenes, ii) 17 tumor suppressor genes, and iii) 16 ambivalent (i.e., genes thath can be both) genes, based on information from the COSMIC database (http://cancer.sanger.ac.uk/cosmic). We excluded contradictory copy number changes, such as gain of tumor suppressors and 


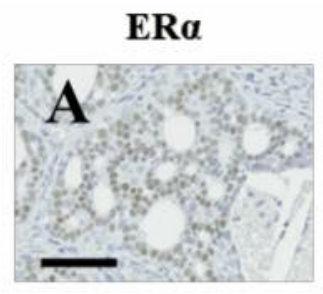

HER2

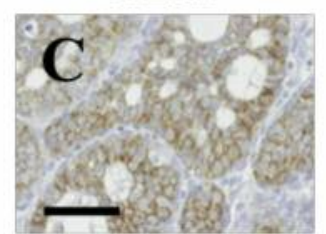

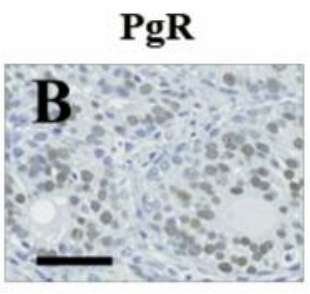

Ki-67

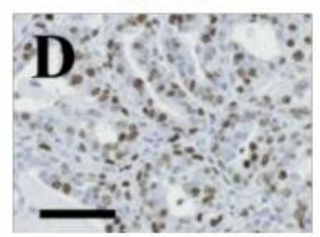

$\mathbf{E}$

\begin{tabular}{cccc}
\hline \multirow{2}{*}{ Marker } & \multicolumn{3}{c}{ Positive cells (\%) } \\
\cline { 2 - 4 } & No irradiation & Neutrons & $\gamma$ rays \\
\hline ER $\alpha$ & $18.6 \pm 2.4$ & $25.4 \pm 3.4$ & $18.5 \pm 2.8$ \\
PgR & $10.1 \pm 2.0$ & $11.3 \pm 2.7$ & $17.4 \pm 2.8$ \\
HER2 & $8.2 \pm 1.8$ & $8.2 \pm 3.0$ & $3.5 \pm 0.8$ \\
Ki-67 & $14.9 \pm 1.7$ & $18.9 \pm 2.6$ & $20.0 \pm 2.0$ \\
\hline
\end{tabular}

Figure 1. Immunohistochemical staining of rat mammary carcinomas. A-D, Representative photomicrographs of mammary carcinoma sections

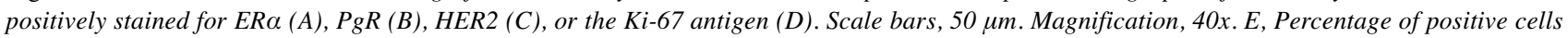
$($ mean $\pm S D)$.

loss of proto-oncogenes and we ultimately obtained 26 aberrations affecting 44 genes, out of which 10 were partialchromosome aberrations (affected genes are listed in Table V). Of note, many of these genes (Erbb2, Erbb3, Pten, Nras, Notch1, Notch2, Smad4, and Apc) encode signal transducers, and their orthologues are mutated in human breast cancer. There were no differences in the distribution of these genes among our three groups (Table V).

These results revealed that the rat mammary carcinomas we analysed had multiple DNA copy number aberrations - either partial- or whole-chromosome - and these aberrations were not associated with tumor etiology (i.e., spontaneous, neutroninduced, or $\gamma$-ray-induced) even though they affected regulatory genes that undergo mutations in human breast cancer.

\section{Discussion}

In the present study, we analysed the subtype and copy number aberrations of rat mammary carcinomas to reveal a mechanism of carcinogenesis induced by neutrons and $\gamma$ rays. We, herein, revealed that these exposures increased the incidence of luminal mammary carcinoma. Although a few studies have investigated the subtype of radiation-induced breast cancer in humans, there has been no consistent evidence that radiation preferentially induces specific subtypes (13-15). Notably, the subtype of breast cancer is influenced by various factors such as the number of births and obesity, and differences in these reproductive and lifestyle factors might underlie the inconsistency among the reported results (23). On the other hand, rats mainly develop hormone receptor-positive mammary carcinomas in both spontaneous and chemical-induced models $(6,17)$. Our present data concerning subtype frequency are consistent with published data (17).
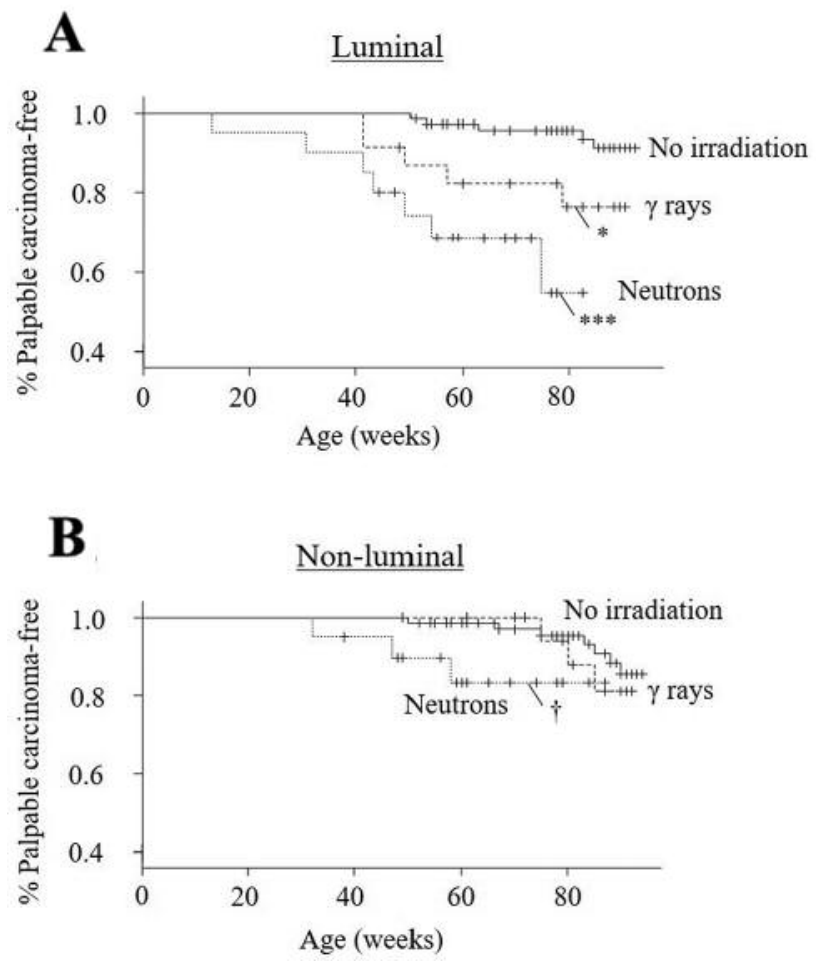

Figure 2. Kaplan-Meier plots showing the onset of luminal (A) and nonluminal $(B)$ palpable mammary carcinomas following irradiation with neutrons or $\gamma$-rays and the spontaneous development of carcinomas in the non-irradiated control. ${ }^{*} p<0.05,{ }^{* * *} p<0.001,{ }^{\dagger} p=0.05, v s$. no irradiation.

Our aCGH analysis revealed copy number aberrations in mammary carcinomas of rats. The number of aberrations we detected here is greater than what we reported previously (24) possibly due to the increased number of cancer cells we 
A No irradiation
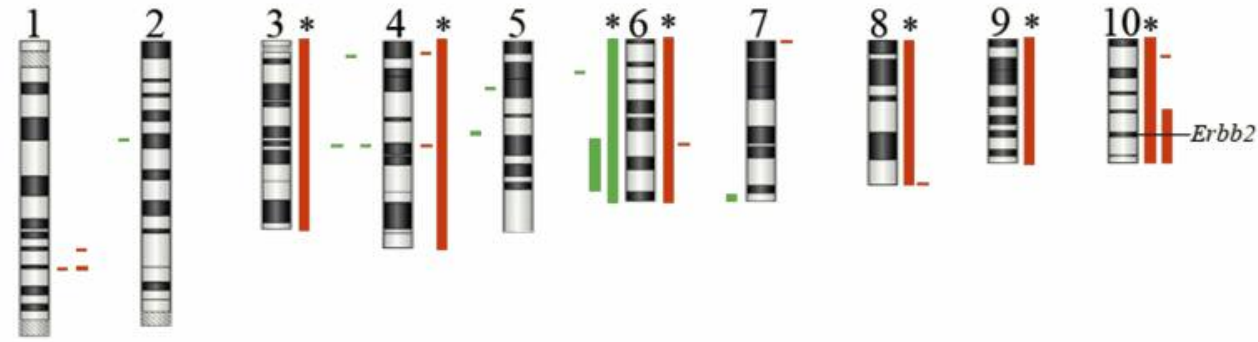

星 $11 *-$

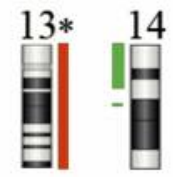

目目
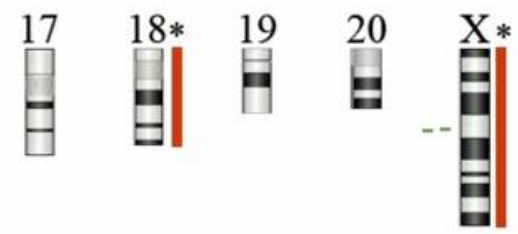

\section{B Neutrons}

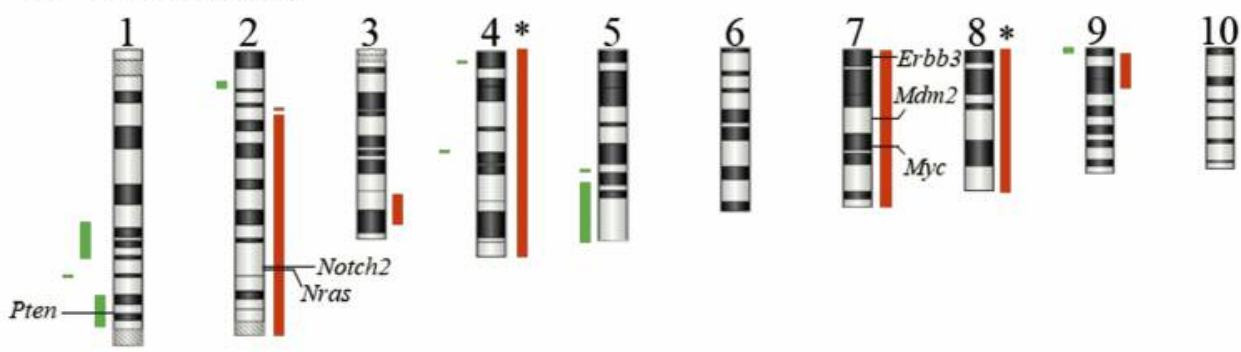

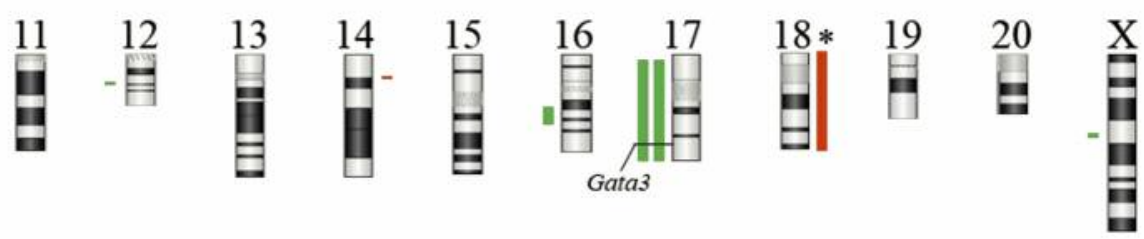

C $\gamma$ rays

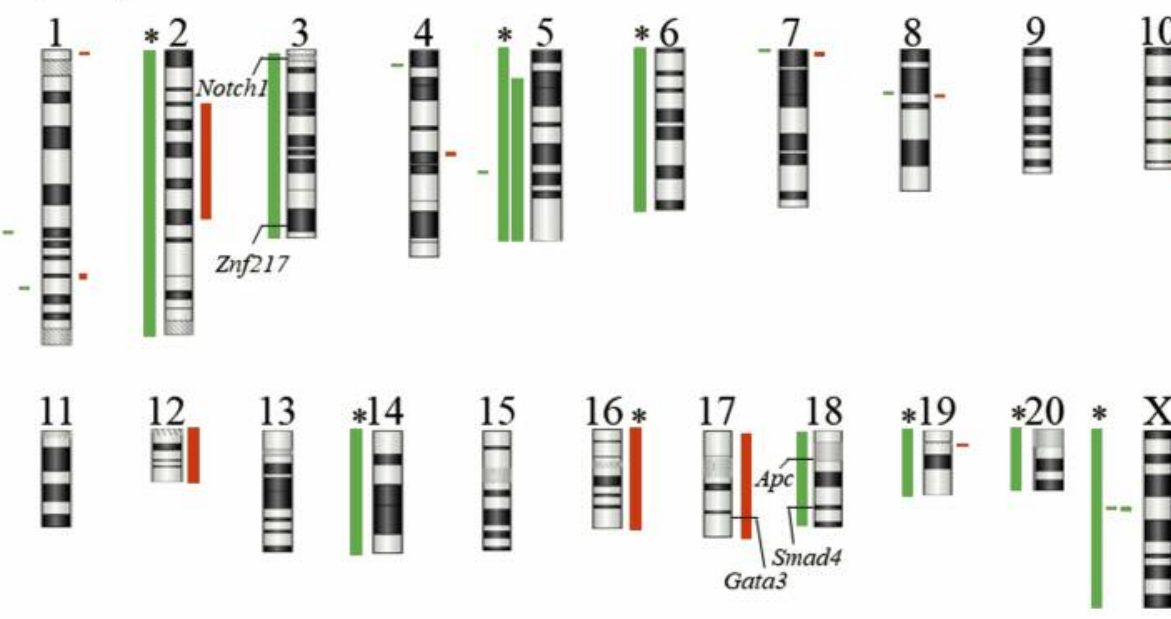

Figure 3. Copy number aberrations identified in rat mammary carcinomas. A, Carcinomas ( $n=7)$ of non-irradiated rats. $B$, Carcinomas ( $n=4)$ of neutron-irradiated rats. $C$, Carcinomas $(n=5)$ of $\gamma$-irradiated rats, showing chromosomal losses (green) and chromosomal gains (red). Aberrations observed in the same carcinoma are arranged vertically, whereas those in different carcinomas are side by side. *Aberration of whole chromosome. 
Table III. Comparison of palpbable mammary carcinoma subtypes among etiologies.

\begin{tabular}{|c|c|c|c|c|}
\hline Feature & Subtype ${ }^{a}$ & No irradiation & Neutrons & $\gamma$ rays \\
\hline \multirow[t]{2}{*}{ Palpable carcinomas } & $\mathrm{L}$ & $8(47 \%)$ & $9(75 \%)$ & $6(67 \%)$ \\
\hline & NL & $9(53 \%)$ & $3(25 \%)$ & $3(33 \%)$ \\
\hline \multirow[t]{2}{*}{ Hazard ratio $[95 \% \mathrm{CI}]$} & $\mathrm{L}$ & 1 (reference) & $9.2[2.8-30.4]^{* * *}$ & $3.5[1.0-12.1]^{*}$ \\
\hline & NL & 1 (reference) & $4.2[1.0-17.6]^{\dagger}$ & $1.6[0.4-5.2]$ \\
\hline \multirow[t]{2}{*}{ Weeks of age at detection ${ }^{b}$} & $\mathrm{~L}$ & $68.5 \pm 14.4$ & $41.5 \pm 20.0^{*}$ & $55.7 \pm 14.3$ \\
\hline & NL & $77.3 \pm 14.0$ & $45.8 \pm 13.3^{* *}$ & $79.9 \pm 5.0$ \\
\hline
\end{tabular}

${ }^{\mathrm{a}} \mathrm{L}$, Luminal; NL, non-luminal. bMean $\pm \mathrm{SD} .{ }^{\dagger} p=0.05,{ }^{*} p<0.05,{ }^{*} p<0.01,{ }^{*} * *<0.001$ vs. no irradiation.

Table IV. Copy number aberrations of partial chromosomes by etiology and subtype.

\begin{tabular}{|c|c|c|c|c|c|}
\hline \multirow[b]{2}{*}{ Feature } & \multicolumn{3}{|c|}{ Etiology } & \multicolumn{2}{|c|}{ Subtype } \\
\hline & No irradiation & Neutrons & $\gamma$ rays & Luminal & Non-luminal \\
\hline Tumors with any aberration & $7 / 7(100 \%)$ & $4 / 4(100 \%)$ & $5 / 5(100 \%)$ & $11 / 11(100 \%)$ & $5 / 5(100 \%)$ \\
\hline With loss & $6 / 7(86 \%)$ & $4 / 4(100 \%)$ & $5 / 5(100 \%)$ & $10 / 11(91 \%)$ & $5 / 5(100 \%)$ \\
\hline With gain & $4 / 7(57 \%)$ & $2 / 4(50 \%)$ & $3 / 5(60 \%)$ & $6 / 11(55 \%)$ & $3 / 5(60 \%)$ \\
\hline No. of aberrations per tumor & $4.3 \pm 3.8^{\mathrm{a}}$ & $6.0 \pm 5.8$ & $4.4 \pm 5.9$ & $3.5 \pm 3.9$ & $7.6 \pm 5.7$ \\
\hline No. of losses & $2.3 \pm 2.1$ & $4.0 \pm 3.5$ & $2.2 \pm 2.2$ & $2.1 \pm 2.5$ & $4.0 \pm 2.0$ \\
\hline No. of gains & $2.0 \pm 2.2$ & $2.0 \pm 2.4$ & $2.2 \pm 3.8$ & $1.4 \pm 1.6$ & $3.6 \pm 3.9$ \\
\hline
\end{tabular}

aMean \pm SD.

Table V. Partial-chromosome copy number aberrations affecting genes associated with human breast cancer.

\begin{tabular}{|c|c|c|c|c|}
\hline Tumor ID & Subtype ${ }^{a}$ & Chromosome & $\begin{array}{l}\text { Copy number } \\
\text { change }\end{array}$ & $\begin{array}{l}\text { Rat orthologue of human gene } \\
\text { associated with breast cancer }{ }^{b}\end{array}$ \\
\hline \multicolumn{5}{|c|}{ A) Spontaneous mammary carcinomas } \\
\hline K2476Mt3 & NL & $10 \mathrm{q} 25-\mathrm{q} 32.3$ & Gain & Erbb2 (POG) \\
\hline \multicolumn{5}{|c|}{ B) Mammary carcinomas induced by neutrons } \\
\hline \multirow[t]{3}{*}{ K2408Mt1 } & $\mathrm{L}$ & 1q51-q54 & Loss & Pten (TSG) \\
\hline & & 7q11-q36 & Gain & $M y c, M d m 2, E r b b 3$ (POG) \\
\hline & & $17 \mathrm{p} 14-\mathrm{q} 12.3$ & Loss & Gata3 (Ambivalent) \\
\hline \multirow{3}{*}{$\begin{array}{l}\text { K2522Mt5 } \\
\text { Notch2 (An }\end{array}$} & $\mathrm{L}$ & $2 q 16-q 45$ & Gain & Nras (POG) \\
\hline & & & & \\
\hline & & $17 \mathrm{p} 14-\mathrm{q} 12.3$ & Loss & Gata3 (Ambivalent) \\
\hline \multicolumn{5}{|c|}{ C) Mammary carcinomas induced by $\gamma$ rays } \\
\hline K1181Mt1 & $\mathrm{L}$ & $10 q 24-q 32.3$ & Gain & Erbb2 (POG) \\
\hline \multirow[t]{3}{*}{ K1433Mt1 } & NL & 3p13-q43 & Loss & Notch1, Znf217 (Ambivalent) \\
\hline & & $17 \mathrm{p} 14-\mathrm{q} 12.3$ & Gain & Gata3 (Ambivalent) \\
\hline & & 18p13-q13 & Loss & Smad4, Apc (TSG) \\
\hline
\end{tabular}

${ }^{a}$ L, Luminal; NL, non-luminal. bBased on Nik-Zainal et al. (2016) (18); POG, proto-oncogene; TSG, tumor suppressor gene.

isolated using laser microdissection. We found that these aberrations were present in a variety of genes that are frequently affected in human breast cancer (22), thus supporting the idea that these aberrations play important functional roles in the development of carcinomas in rats. On the other hand, we did not find any significant difference among the carcinomas in all our groups with regards to the frequency, the number, or the identity of genes for which copy 
number aberrations were apparent . This observation suggests that the molecular mechanism of mammary carcinogenesis induced by neutron or $\gamma$-ray irradiation is similar to that of spontaneous tumor development, at least with respect to copy number aberrations. This does not indicate, however, whether the type of radiation has any influence on carcinogenesis, as the age at which tumors were detected was earlier and the hazard ratio was greater for rats in the irradiated groups compared to those in ethe non-irradiated group. Thus, irradiation may have increased the probability of the occurrence of these copy number aberrations, or it has shortened the onset period. In the present study we did not analyze other types of mutations except for copy number aberrations, thus, further analysis is warranted, using more comprehensive techniques, such as next-generation sequencing.

Our results indicate that the increased incidence of rat mammary carcinoma caused by exposure to neutrons or $\gamma$ rays could primarily account for an increased incidence of luminal carcinoma. Finally, these results also suggest that copy number aberrations affecting genes associated with human breast cancer are involved in the mechanism of tumorigenesis, providing information on previously unknown aspects of breast cancer development following exposure to neutrons.

\section{Conflicts of Interest}

The Authors declare that there are no confricts of interest.

\section{Authors' Contributions}

HM, KD, TI, MN, YN, MT and TM designed the study and performed experiments. HM, KD, TI and MT analyzed the data and drafted the manuscript. MF, YS and KS supervised the work and helped draft and revise the manuscript. All authors read and approved the final manuscript.

\section{Acknowledgements}

This work was supported, in part, by a Grant-in-Aid for Young Scientists (B) JP26740022 and for Scientific Research (A) JP15H01834 from the Japan Society for the Promotion of Science KAKENHI. We thank all the technical staff at the Department of Radiation Effects Research, National Institutes of Radiological Sciences, and National Institute for Quantum and Radiological Science and Technology.

\section{References}

1 Preston DL, Ron E, Tokuoka S, Funamoto S, Nishi N, Soda M, Mabuchi K and Kodama K: Solid Cancer Incidence in Atomic Bomb Survivors: 1958-1998. Radiat Res 168: 1-64, 2007. PMID: 17722996, DOI: 10.1667/rr0763.1

2 Covelli V, Coppola M, Di Majo V and Rebessi S: The doseresponse relationships for tumor induction after high-LET radiation. J Radiat Res 32(Suppl 2): 110-117, 1991. PMID: 1823348
3 Taddei PJ, Mahajan A, Mirkovic D, Zhang R, Giebeler A, Kornguth D, Harvey $M$, Woo $S$ and Newhauser WD: Predicted risks of second malignant neoplasm incidence and mortality due to secondary neutrons in a girl and boy receiving proton craniospinal irradiation. Phys Med Biol 55: 7067-7080, 2010. PMID: 21076189, DOI: 10.1088/00319155/55/23/S08

4 Vogelstein B, Papadopoulos N, Velculescu VE, Zhou S, Diaz LA and Kinzler KW: Cancer Genome Landscapes. Science 339: 1546-1558, 2013. PMID: 23539594, DOI: 10.1126/ science. 1235122

5 Esteller M: Epigenetics in cancer. N Engl J Med 358: 11481159, 2008. PMID: 18337604, DOI: 10.1056/NEJMra072067

6 Russo J: Significance of rat mammary tumors for human risk assessment. Toxicol Pathol 43: 145-170, 2015. PMID 25714400, DOI: $10.1177 / 0192623314532036$

7 Imaoka T, Nishimura M, Iizuka D, Daino K, Takabatake T, Okamoto M, Kakinuma S and Shimada Y: Radiation-Induced mammary carcinogenesis in rodent models: What's different from chemical carcinogenesis? J Radiat Res 50: 281-293, 2009. PMID: 19506345, DOI: 10.1269/jrr.09027

8 Imaoka T, Nishimura M, Daino K, Hosoki A, Takabatake M, Kokubo T, Doi K, Showler K, Nishimura Y, Moriyama H, Morioka T, Shimada Y, and Kakinuma S: Age modifies the effect of 2-MeV fast neutrons on rat mammary carcinogenesis. Radiat Res 188: 419-425, 2017. PMID: 28809605, DOI: $10.1667 / \operatorname{rr} 14829.1$

9 Showler K, Nishimura M, Daino K, Imaoka T, Nishimura Y, Morioka T, Blyth BJ, Kokubo T, Takabatake M, Fukuda M, Moriyama H, Kakinuma S, Fukushi $M$ and Shimada $Y$ : Analysis of genes involved in the PI3K/Akt pathway in radiation- and MNU-induced rat mammary carcinomas. J Radiat Res 58: 183-194, 2016. PMID: 27738081, DOI: $10.1093 /$ jrr/rrw097

10 Daino K, Nishimura M, Imaoka T, Takabatake M, Morioka T, Nishimura $\mathrm{Y}$, Shimada $\mathrm{Y}$ and Kakinuma S: Epigenetic dysregulation of key developmental genes in radiation-induced rat mammary carcinomas. Int J Cancer 143: 343-354, 2018. PMID: 29435983, DOI: 10.1002/ijc.31309

11 Imaoka T, Nishimura M, Daino K, Takabatake M, Moriyama H, Nishimura Y, Morioka T, Shimada Y and Kakinuma S: Risk of second cancer after ion beam radiotherapy: insights from animal carcinogenesis studies. Int J Radiat Biol 29: 1-33, 2018. PMID: 30495977, DOI: 10.1080/09553002.2018.1547848

12 Coates AS, Winer EP, Goldhirsch A, Gelber RD, Gnant M, Piccart-Gebhart M, Thurlimann B and Senn HJ: Tailoring therapies--improving the management of early breast cancer: $\mathrm{St}$ Gallen International Expert Consensus on the Primary Therapy of Early Breast Cancer 2015. Ann Oncol 26: 1533-1546, 2015. PMID: 25939896, DOI: 10.1093/annonc/mdv221

13 Neta G, Anderson WF, Gilbert E and Berrington A: Variation in the risk of radiation-related contralateral breast cancer by histology and estrogen receptor expression in SEER. Breast Cancer Res Treat 131: 1021-1027, 2012. PMID: 22015617, DOI: 10.1007/s 10549-011-1820-8

14 Broeks A, Braaf LM, Wessels LF, van de Vijver M, De Bruin ML, Stovall M, Russell NS, van Leeuwen FE and Van't Veer LJ: Radiation-associated breast tumors display a distinct gene expression profile. Int J Radiat Oncol Biol Phys 76: 540-547, 2010. PMID: 20117289, DOI: 10.1016/j.ijrobp.2009.09.004 
15 Yang XR, Killian JK, Hammond S, Burke LS, Bennett H, Wang Y, Davis SR, Strong LC, Neglia J, Stovall M, Weathers RE, Robison LL, Bhatia S, Mabuchi K, Inskip PD and Meltzer P: Characterization of genomic alterations in radiation-associated breast cancer among childhood cancer survivors, using comparative genomic hybridization (CGH) arrays. PloS one 10: e0116078, 2015. PMID: 25764003, DOI: 10.1371/journal.pone.0116078

16 Imaoka T, Nishimura M, Daino K, Kokubo T, Doi K, lizuka D, Nishimura Y, Okutani T, Takabatake M, Kakinuma S and Shimada $\mathrm{Y}$ : Influence of age on the relative biological effectiveness of carbon ion radiation for induction of rat mammary carcinoma. Int J Radiat Oncol Biol Phys 85: 1134-1140, 2013. PMID: 23084769, DOI: $10.1016 /$ j.ijrobp.2012.08.035

17 Takabatake M, Daino K, Imaoka T, Blyth BJ, Kokubo T, Nishimura Y, Showler K, Hosoki A, Moriyama H, Nishimura M, Kakinuma S, Fukushi M and Shimada Y: Differential effect of parity on rat mammary carcinogenesis after pre- or post-pubertal exposure to radiation. Sci Rep 8: 14325, 2018. PMID: 30254198, DOI: 10.1038/s41598-018-32406-1

18 Kanda Y: Investigation of the freely available easy-to-use software 'EZR' for medical statistics. Bone Marrow Transplant 48: 452-458, 2013. PMID: 23208313, DOI: 10.1038/ bmt.2012.244

19 Vignard J, Mirey G and Salles B: Ionizing-radiation induced DNA double-strand breaks: a direct and indirect lighting up. Radiother Oncol 108: 362-369, 2013. PMID: 23849169, DOI: 10.1016/j.radonc.2013.06.013

20 Compton DA: Mechanisms of aneuploidy. Curr Opin Cell Biol 23: 109-113, 2011. PMID: 23849169, DOI: 10.1016/ j.radonc. 2013.06.013

21 Holland AJ and Cleveland DW: Boveri revisited: chromosomal instability, aneuploidy and tumorigenesis. Nat Rev Mol Cell Biol 10: 478-487, 2009. PMID: 19546858, DOI: 10.1038/nrm2718

22 Nik-Zainal S, Davies H, Staaf J, Ramakrishna M, Glodzik D, Zou X, Martincorena I, Alexandrov LB, Martin S, Wedge DC, Van Loo P, Ju YS, Smid M, Brinkman AB, Morganella S, Aure
MR, Lingjaerde OC, Langerod A, Ringner M, Ahn SM, Boyault S, Brock JE, Broeks A, Butler A, Desmedt C, Dirix L, Dronov S, Fatima A, Foekens JA, Gerstung M, Hooijer GK, Jang SJ, Jones DR, Kim HY, King TA, Krishnamurthy S, Lee HJ, Lee JY, Li Y, McLaren S, Menzies A, Mustonen V, O'Meara S, Pauporte I, Pivot X, Purdie CA, Raine K, Ramakrishnan K, RodriguezGonzalez FG, Romieu G, Sieuwerts AM, Simpson PT, Shepherd R, Stebbings L, Stefansson OA, Teague J, Tommasi S, Treilleux I, Van den Eynden GG, Vermeulen P, Vincent-Salomon A, Yates L, Caldas C, van't Veer L, Tutt A, Knappskog S, Tan BK, Jonkers J, Borg A, Ueno NT, Sotiriou C, Viari A, Futreal PA, Campbell PJ, Span PN, Van Laere S, Lakhani SR, Eyfjord JE, Thompson AM, Birney E, Stunnenberg HG, van de Vijver MJ, Martens JW, Borresen-Dale AL, Richardson AL, Kong G, Thomas G and Stratton MR: Landscape of somatic mutations in 560 breast cancer whole-genome sequences. Nature 534: 47-54, 2016. PMID: 27135926, DOI: 10.1038/nature17676

23 Turkoz FP, Solak M, Petekkaya I, Keskin O, Kertmen N, Sarici F, Arik Z, Babacan T, Ozisik Y and Altundag K: Association between common risk factors and molecular subtypes in breast cancer patients. Breast 22: 344-350, 2013. PMID: 22981738, DOI: $10.1016 /$ j.breast 2012.08 .005

24 Iizuka D, Imaoka T, Takabatake T, Nishimura M, Kakinuma S, Nishimura Y and Shimada Y: DNA copy number aberrations and disruption of the $\mathrm{p} 16 \mathrm{Ink} 4 \mathrm{a} / \mathrm{Rb}$ pathway in radiation-induced and spontaneous rat mammary carcinomas. Radiat Res 174: 206-215, 2010. PMID: 20681787, DOI: 10.1667/RR2006.1 